\title{
Identification of introgressed alien chromosome segments associated with grain quality in Oryza rufipogon $x$ MR219 advanced breeding lines using SSR markers
}

\author{
P. Fasahat ${ }^{1}$, K. Muhammad ${ }^{2}$, A. Abdullah ${ }^{3}$ and R. Wickneswari ${ }^{1}$ \\ ${ }^{1}$ School of Environmental and Natural Resource Sciences, \\ National University of Malaysia, Kuala Lumpur, Malaysia \\ ${ }^{2}$ Department of Food Science, University Putra Malaysia, \\ Kuala Lumpur, Malaysia \\ ${ }^{3}$ School of Chemical Science and Food Technology, \\ National University of Malaysia, Kuala Lumpur, Malaysia \\ Corresponding author: R. Wickneswari \\ E-mail: wicki@ukm.my
}

Genet. Mol. Res. 11 (3): 3534-3546 (2012)

Received January 10, 2012

Accepted March 23, 2012

Published September 26, 2012

DOI http://dx.doi.org/10.4238/2012.September.26.10

\begin{abstract}
A limited backcross procedure was utilized to introgress genes associated with grain quality traits from Oryza rufipogon (Accession No. IRGC 105491), a wild rice from Malaysia, to the cultivated rice $O$. sativa cv. MR219, a popular high yielding Malaysian rice cultivar. A set of $10 \mathrm{BC}_{2} \mathrm{~F}_{7}$ progenies were selected based on the field performance and phenotypic appearance in $\mathrm{BC}_{2} \mathrm{~F}_{5}$ and $\mathrm{BC}_{2} \mathrm{~F}_{6}$ generations, which initially started with 266 progenies in the $\mathrm{BC}_{2} \mathrm{~F}_{2}$ generation. These 10 advanced breeding lines are similar to each other but differ in several important grain quality traits, which can be traced to O. rufipogon introgressions. Phenotyping and genotyping of $\mathrm{BC}_{2} \mathrm{~F}_{7}$ variants were considered for QTL analysis. The introgressed lines did not show any significant changes compared to the recurrent parent MR219 for the traits grain density and milled rice percentage. All 10 progenies showed significantly higher head rice percentages (70-88\%) than the recurrent parent
\end{abstract}


MR219. Variants G13 and G15 had higher amylose contents than MR219. All variants were analyzed using polymorphic SSR markers. Of the 34 SSR markers, only 18 showed introgression from $O$. rufipogon for chromosomes $1,2,3,5,6,8,10$, and 11 . Graphical genotypes were prepared for each variant, and association between the introgression regions and the traits that increased grain quality was visualized. Based on marker trait association, some of the QTLs are stable across environments and genetic backgrounds and could be used universally.

Key words: Advanced breeding lines; Grain quality; Molecular analysis

\section{INTRODUCTION}

Nearly two-thirds of the world's population consumes rice (Oryza sativa L.) as the staple food. It has been reported that as much as $75 \%$ of the daily calorie intake of the people in some Asian countries is derived from rice. The genus Oryza comprises more than 20 wild and two cultivated species. The wild species of Oryzae are an important source of genetic variation for agronomic traits such as resistance to various biotic and abiotic stresses and for improved yield potential (Brar and Khush, 1997). Since the wild germplasm has not been thoroughly exploited yet, there is still a great potential to develop new modern rice varieties by incorporating new useful genes from wild races. The common wild rice $O$. rufipogon is the most important genetic resource for rice improvement in terms of its accessibility from gene transfer through sexual means (Oka, 1988). It is widely distributed in South and Southeast Asian countries, including Malaysia where $O$. sativa is a major staple food and extensively cultivated.

Discovery of the productivity-increasing potential of alien genes came primarily from the study of Frey et al. (1983) in oats. Tanksley et al. (1996) conceived the synergistic association of QTL mapping and alien gene introgression and suggested the AB-QTL strategy. Next, mining of productivity QTLs from wild and exotic donors (usually having the same genome completion as the recipient) under parallel backcrossing and evaluation, together with molecular marker analysis, appeared to be a powerful plant breeding strategy. The first successful utilization of this method in rice (Xiao et al., 1996, 1998) increased interest considerably. In that study, chromosome segments from a Malaysian accession of $O$. rufipogon (IRGC 105491) resulted in a yield increase in the $\mathrm{BC}_{3}$ testcross progeny, using parental lines of an elite hybrid variety from China as recurrent parent. The present study used the Malaysian accession of O. rufipogon (IRGC 105491) in context of a pure line recipient (MR219), which is known for its high yield. Two other studies with the same O. rufipogon accession but different recipient genotypes for productivity genes were carried out in previous studies (Thomson et al., 2003; Septiningsih et al., 2003). All these studies evaluated alien gene introgression and its phenotypic expression in the segregating phase.

Studies showing grain quality improvement in the homozygous final product are important from a plant breeding viewpoint, and the present study attempted to provide this information. However, the AB-QTL strategy of molecular mapping did not accompany this study, with molecular analysis being limited to the identification of alien chromatin regions in stable homozygous lines. However, utilization of an O. rufipogon accession that has been used in other studies, with different recipients, also allowed beneficial comparisons particularly regarding the adaptability of specific QTL under different environments and backgrounds. 


\section{MATERIAL AND METHODS}

\section{Population development}

In the year 2003, an advanced backcross program using a wide hybridization between O. rufipogon and MR219, focusing on the development of a high-yielding rice cultivar was started by Wickneswari et al. (2003). Twenty-six transgressive variants were identified as promising for cultivar development after a successful pedigree selection in the $\mathrm{BC}_{2} \mathrm{~F}_{3}$ and $\mathrm{BC}_{2} \mathrm{~F}_{4}$ generations. The variants (Table 1) used in the present study were selected based on field performance and pericarp color in the $\mathrm{BC}_{2} \mathrm{~F}_{5}$ and $\mathrm{BC}_{2} \mathrm{~F}_{6}$ generations in three different environments over two seasons (off season and main season). Based on the yield per hectare parameter, variants G7, G13 and G16 out-yielded the check cultivar, MR219. The code for the variants was used for easy reference in future studies. The selected variants were considered as treatments and assigned in the completely randomized design with two replications. These 10 variants were further evaluated for grain quality and analyzed for $O$. rufipogon introgression using SSR markers as presented in following sections.

\section{Physicochemical properties}

Grain density is a measure of weight per volume, in this case measured as the weight of rough rice grains per liter. Filled rough/total rough rice ratio was calculated as the weight of filled rough rice grains and taken as a percentage; to estimate filled grains ratio, two random sets of 100 grains each from harvested grains were taken. Percentage of de-husked rice grains was the percentage of the weight of de-husked grains compared to the weight of the sample of rough rice. Husks were removed from $100 \mathrm{~g}$ grains in duplicate to obtain brown rice (Septinigsih et al., 2003). Percentage of milled rice grains was calculated as the weight of milled rice grains divided by the weight of the sample of rough rice (using a sample of total de-husked rice of a 300-g sample of rough rice) and taken as a percentage. Percentage of head rice was calculated as the weight of whole grain or part of grain with a length greater than or equal to three-quarters of the average length of the test sample kernels divided by the weight of the milled rice sample and stated as a percentage (Septinigsih et al., 2003). Broken rice grains were divided into large broken grains, medium broken grains, small broken grains, and chips (Septinigsih et al., 2003). The sum of all data obtained divided by the weight of milled rice sample was stated as a percentage of broken rice grains.

The length, width and thickness of brown rice (50 grains per sample) were measured with the help of a digital micrometer (Steinmeyer, Germany). Size and shape were determined according to the RTWG (1997). Rice samples were analyzed for protein [by standard Kjeldahl procedure (MS1194, 1991)] and amylose content. Amylose was measured following the International Standard for determination in rice (ISO/DIS 6647-1 and 6647-2, 2005) using the FIAFOSS Sampler 5027 autoanalyzer (FOSS, Hoganas, Sweden).

\section{Marker analysis}

DNA was extracted from the leaves at the age of 14 days following the modified chloroform-based DNA extraction protocol by Murray and Thompson (1980) and using the DNeasy 
Plant Mini kit (Qiagen, Germany). PCR conditions were as described by Panaud et al. (1996). Primer sets of 69 microsatellites were used for analyzing the introgression regions and selected from the Gramene database (www.gramene.org) related to grain quality; it has been mapped by Septiningsih et al. (2003) and Aluko et al. (2004). Markers were initially used for parental polymorphism survey using a $2 \%$ high-resolution agarose gel. The SSR markers that were monomorphic were replaced by SSR markers located nearby (www.gramene.org). Additional markers were analyzed around the region that showed introgression. Of 69 SSR markers, a total of 34 polymorphic SSR markers were used for analyzing the introgression lines. The forward markers were fluorescent-labeled at the 5'-end with FAM (blue), HEX (green), NED (yellow), or PET (red) and synthesized by the 1stBase Company. Six panels of fluorescentlabeled microsatellite markers were created for this study. PCR products were sent to 1 stBase Company for fragment detection. Fragment lengths (allele size) were estimated and scored with the GeneMapper version 4.0 software. Fragment size of the variants in the $\mathrm{BC}_{2} \mathrm{~F}_{7}$ generation was determined following the procedure used by Bhuiyan et al. (2011) with the graphical genotyping GGT 2.0 software (van Berloo, 2008). The variants that showed the size of both alleles to be similar to the recurrent parent (MR219) were scored as A and similar to the donor parent (O. rufipogon) as B. The variants that showed the allele size of both parents were scored as $\mathrm{H}$.

The significance of differences between treatment means was determined by analysis of variance (ANOVA) using SAS version 9.1 (SAS Institute, Cary, NC, USA) with a significant level of 0.05 . The Duncan multiple range test $(a=0.05)$ was determined for mean separation using the SAS software.

\section{RESULTS}

\section{Physicochemical performance of introgression lines}

Based on field performance and pericarp color, a set of 10 introgression lines (Table 1) was selected for further grain quality evaluation and molecular analysis. On the basis of rough rice hull color, all samples were the "straw hull" type and awnless, and based on the length and length/breadth ratio, all samples could be classified as the long and slender variety (Figure 1). A strict selection for improving the grain type of MR219 was conducted in each generation, and the variants selected for grain quality evaluation had a physical appearance of a grain type resembling the recurrent parent MR219 (Figure 1).

\begin{tabular}{|c|c|c|}
\hline S1. No. & MARDI rice gene bank designation $\left(\mathrm{BC}_{2} \mathrm{~F}_{7}\right)$ & Variant code \\
\hline 1 & R2-10-18-2-B-B & G4 \\
\hline 2 & R6-2-31-2-B-B & G7 \\
\hline 3 & R7-6-38-2-B-B & G8 \\
\hline 4 & R7-7-39-4-B-B & G9 \\
\hline 5 & R14-9-69-2-B-B & G13 \\
\hline 6 & R14-9-69-4-B-B & G15 \\
\hline 7 & R14-9-69-5-B-B & G16 \\
\hline 8 & R17-1-83-3-B-B & G19 \\
\hline 9 & R26-2-108-1-B-B & G25 \\
\hline 10 & R26-6-113-1-B-B & G26 \\
\hline 11 & MR219 (control) & \\
\hline
\end{tabular}




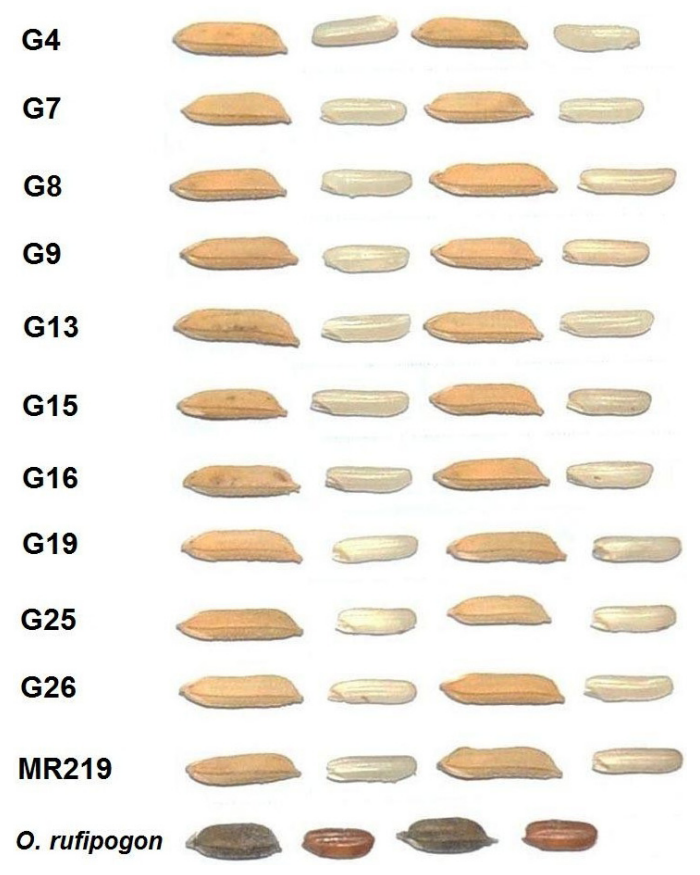

Figure 1. Grain type of parents and selected transgressive variants.

Analysis of variance revealed significant genotypic differences for filled rough rice ratio, de-husked rice percentage, head rice percentage, broken rice percentage, and protein and amylose content. Actual values for significant traits are presented in Table 2.

Table 2. Physicochemical properties of $\mathrm{BC}_{2} \mathrm{~F}_{7} \mathrm{MR} 219 /$ Oryza rufipogon introgression lines averaged over replications.

\begin{tabular}{|c|c|c|c|c|c|c|c|c|}
\hline Line No. & $\begin{array}{c}\text { Grain } \\
\text { density }(\mathrm{g} / \mathrm{L})\end{array}$ & $\begin{array}{l}\text { Filled rough } \\
\text { rice ratio }(\%)\end{array}$ & $\begin{array}{l}\text { De-husked } \\
\text { rice }(\%)\end{array}$ & $\begin{array}{l}\text { Milled } \\
\text { rice }(\%)\end{array}$ & $\begin{array}{c}\text { Head } \\
\text { rice }(\%)\end{array}$ & $\begin{array}{l}\text { Broken } \\
\text { rice }(\%)\end{array}$ & $\begin{array}{c}\text { Protein } \\
\text { content }(\%)\end{array}$ & $\begin{array}{l}\text { Amylose } \\
\text { content (\%) }\end{array}$ \\
\hline G4 & $583.8^{\mathrm{ns}}$ & $98.0^{\mathrm{c}}$ & $79.6^{\text {bcd }}$ & $77.0^{\mathrm{ns}}$ & $77.2^{\mathrm{de}}$ & $22.5^{\mathrm{cd}}$ & $9.4^{\mathrm{a}}$ & $22.6^{c}$ \\
\hline G7 & 634.8 & $98.0^{c}$ & $80.1^{\text {abcd }}$ & 77.6 & $88.5^{\mathrm{a}}$ & $11.2^{\mathrm{f}}$ & $7.9^{c}$ & $19.2^{\mathrm{e}}$ \\
\hline G8 & 601.6 & $99.0^{\mathrm{ab}}$ & $79.8^{\text {bcd }}$ & 76.5 & $70.9^{f}$ & $28.5^{\mathrm{b}}$ & $8.8^{\mathrm{b}}$ & $20.7^{d}$ \\
\hline G9 & 587.2 & $96.5^{\mathrm{d}}$ & $80.1^{\text {abc }}$ & 77.1 & $77.3^{\mathrm{de}}$ & $22.3^{\mathrm{cd}}$ & $8.1^{\mathrm{c}}$ & $25.1^{\mathrm{b}}$ \\
\hline G13 & 584.9 & $99.0^{\mathrm{ab}}$ & $80.4^{\mathrm{ab}}$ & 77.4 & $81.2^{\mathrm{bc}}$ & $18.3^{\mathrm{e}}$ & $8.1^{\mathrm{c}}$ & $25.7^{\mathrm{a}}$ \\
\hline G15 & 600.0 & $99.5^{\mathrm{a}}$ & $79.3^{\mathrm{d}}$ & 75.5 & $72.9^{f}$ & $26.6^{\mathrm{b}}$ & $9.0^{\mathrm{ab}}$ & $25.7^{\mathrm{a}}$ \\
\hline G16 & 600.3 & $98.0^{\mathrm{c}}$ & $79.6^{\mathrm{bcd}}$ & 77.0 & $82.7^{\mathrm{b}}$ & $17.0^{\mathrm{e}}$ & $9.2^{\mathrm{ab}}$ & $20.6^{\mathrm{d}}$ \\
\hline G19 & 617.0 & $98.0^{\mathrm{c}}$ & $80.0^{\mathrm{abcd}}$ & 76.6 & $74.1^{\text {ef }}$ & $25.2^{\mathrm{bc}}$ & $9.0^{\mathrm{ab}}$ & $22.7^{\mathrm{c}}$ \\
\hline G25 & 579.1 & $98.0^{c}$ & $80.6^{\mathrm{a}}$ & 77.1 & $81.6^{\mathrm{bc}}$ & $18.1^{\mathrm{e}}$ & $9.2^{\mathrm{ab}}$ & $18.4^{\mathrm{f}}$ \\
\hline G26 & 590.1 & $98.5^{\mathrm{bc}}$ & $80.0^{\mathrm{abcd}}$ & 77.4 & $78.4^{\mathrm{cd}}$ & $20.8^{\mathrm{de}}$ & $9.5^{\mathrm{a}}$ & $20.8^{d}$ \\
\hline MR219 & 608.8 & $99.0^{\mathrm{ab}}$ & $79.5^{\text {cd }}$ & 72.7 & $60.2^{\mathrm{g}}$ & $39.2^{\mathrm{a}}$ & $9.2^{\mathrm{ab}}$ & $25.1^{b}$ \\
\hline CV(\%) & 2.4 & 0.3 & 0.4 & 1.6 & 2.1 & 7.5 & 2.3 & 0.4 \\
\hline
\end{tabular}

Means with the same letter are not significantly different. ns = not significant; $\mathrm{CV}=$ coefficient of variation.

Grain density was not significantly different among variants. Filled rough/total rough rice ratio was slightly skewed toward higher values, suggesting that most of the variants had good filled rough counts. As for grain quality components, de-husked rice percentage showed a distinct increase in all lines. However, variation for milled rice percentage turned out to be 
nonsignificant. All variants gave appreciably higher milling percentages (above 70\%). A 50\% milling out turn or less is undesirable since it means that $50 \%$ of the rice are discarded as husk and bran after milling. All the evaluated lines showed significantly higher head rice percentage compared to MR219, and the increase over MR219 in these variants ranged from $10.9 \%$ (G8) to $28.4 \%$ (G7) (Table 2). Broken rice percentage showed improvement in all variants with lower levels than in MR219. The statistical results revealed that the protein content was significantly affected by the rice variants and ranged from 7.9 to $9.5 \%$. Two of the 10 variants evaluated showed significantly $(\mathrm{P}<0.01)$ higher amylose content relative to MR219. Genotype G9 was statistically at par with MR219 for amylose content (Table 2).

\section{Marker analysis and development of graphical genotypes}

Of the 34 polymorphic markers spanning 10 chromosomes, only 18 showed $O$. rufipogon introgression in 10 selected $\mathrm{BC}_{2} \mathrm{~F}_{7}$ progenies (Table 3 ). The banding patterns of microsatellite primer pairs for polymorphic marker RM13345 linked with head rice and broken rice percentage genes for 10 samples along with two parents are shown in Figure 2. The majority of markers were skewed towards MR219, which may be explained by the two backcrosses and subsequent selection during population development.

Table 3. Information on the polymorphic microsatellite markers used for introgression analysis in rice.

\begin{tabular}{|c|c|c|c|c|c|}
\hline \multirow{2}{*}{$\begin{array}{l}\text { SSR } \\
\text { markers }\end{array}$} & \multicolumn{2}{|c|}{ Primer sequences $\left(5^{\prime}-3^{\prime}\right)$} & \multirow[t]{2}{*}{ Chromosome } & \multirow{2}{*}{$\begin{array}{c}\text { Repeat } \\
\text { motif }\end{array}$} & \multirow{2}{*}{$\begin{array}{l}\text { Expected } \\
\text { PCR product } \\
\text { size (bp) }\end{array}$} \\
\hline & F: sequence of forward primer & $\mathrm{R}$ : sequence of reverse primer & & & \\
\hline RM5 & TGCAACTTCTAGCTGCTCGA & GCATCCGATCTTGATGGG & 1 & $(\mathrm{GA})_{14}$ & 113 \\
\hline RM23 & CATTGGAGTGGAGGCTGG & GTCAGGCTTCTGCCATTCTC & 1 & $(\mathrm{GA})_{15}^{14}$ & 145 \\
\hline RM297 & TCTTTGGAGGCGAGCTGAG & CGAAGGGTACATCTGCTTAG & 1 & $(\mathrm{GA})_{13}^{15}$ & 148 \\
\hline RM493 & TAGCTCCAACAGGATCGACC & GTACGTAAACGCGGAAGGTG & 1 & $(\mathrm{CTT})_{9}$ & 211 \\
\hline RM572 & CGGTTAATGTCATCTGATTGG & TTCGAGATCCAAGACTGACC & 1 & $(\mathrm{TC})_{14}$ & 159 \\
\hline RM263 & CCCAGGCTAGCTCATGAACC & GCTACGTTTGAGCTACCACG & 2 & $(\mathrm{CT})_{34}^{14}$ & 199 \\
\hline RM240 & CCTTAATGGGTAGTGTGCAC & TGTAACCATTCCTTCCATCC & 2 & $(\mathrm{CT})_{21}^{34}$ & 132 \\
\hline RM13345 & СТTCTCCTGCTCCTCCCGATCC & CTTCCATGGCTGTCCGTCTTACC & 2 & $(\mathrm{TCT})_{10}$ & 167 \\
\hline RM7 & TTCGCCATGAAGTCTCTCG & CCTCCCATCATTTCGTTGTT & 3 & $(\mathrm{GA})_{10}$ & 180 \\
\hline RM251 & GAATGGCAATGGCGCTAG & ATGCGGTTCAAGATTCGATC & 3 & $(\mathrm{CT})_{20}$ & 147 \\
\hline RM26 & GAGTCGACGAGCGGCAGA & CTGCGAGCGACGGTAACA & 5 & $(\mathrm{GA})_{15}^{29}$ & 112 \\
\hline RM178 & TCGCGTGAAAGATAAGCGGCGC & GATCACCGTTCCCTCCGCCTGC & 5 & $(\mathrm{GA})_{5}(\mathrm{AG})_{8}$ & 117 \\
\hline RM334 & GTTCAGTGTTCAGTGCCACC & GACTTTGATCTTTGGTGGACG & 5 & $(\mathrm{CTT})_{20}$ & 182 \\
\hline RM253 & TCCTTCAAGAGTGCAAAACC & GCATTGTCATGTCGAAGCC & 6 & $(\mathrm{GA})_{25}^{20}$ & 141 \\
\hline RM540 & GCCTTCTGGCTCATTTATGC & CTAGGCCTGCCAGATTGAAC & 6 & $(\mathrm{AG})_{16}^{25}$ & 172 \\
\hline RM264 & GTTGCGTCCTACTGCTACTTC & GATCCGTGTCGATGATTAGC & 8 & $(\mathrm{GA})_{27}^{16}$ & 178 \\
\hline RM239 & TACAAAATGCTGGGTACCCC & ACATATGGGACCCACCTGTC & 10 & $(\mathrm{AG})_{5} \mathrm{TG}(\mathrm{AG})_{2}$ & 144 \\
\hline RM229 & CACTCACACGAACGACTGAC & CGCAGGTTCTTGTGAAATGT & 11 & $(\mathrm{TC})_{11}(\mathrm{CT})_{5} \mathrm{C}_{3}(\mathrm{CT})_{5}$ & 116 \\
\hline
\end{tabular}

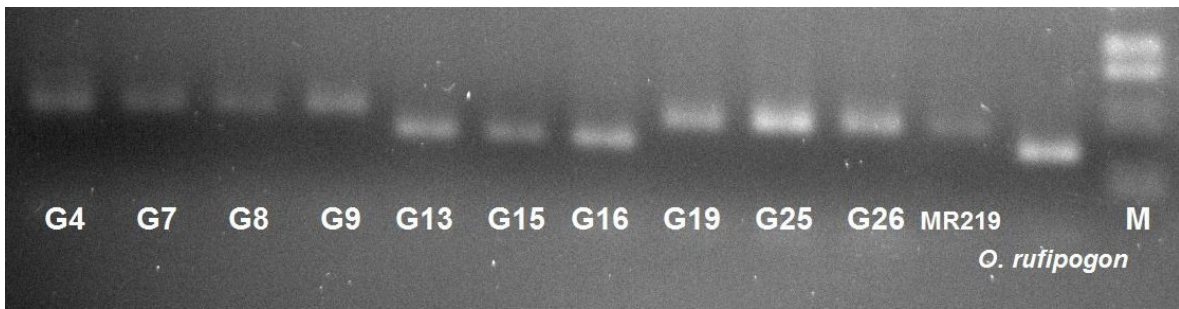

Figure 2. Marker banding patterns in $\mathrm{BC}_{2} \mathrm{f}_{7}$ population for SSR marker RM13345. Lane $M=$ molecular marker. 
The number of markers tested on each chromosome along with the number showing O. rufipogon introgression are given in Figure 3. In this material, no introgression was observed for chromosomes 4 and 7.

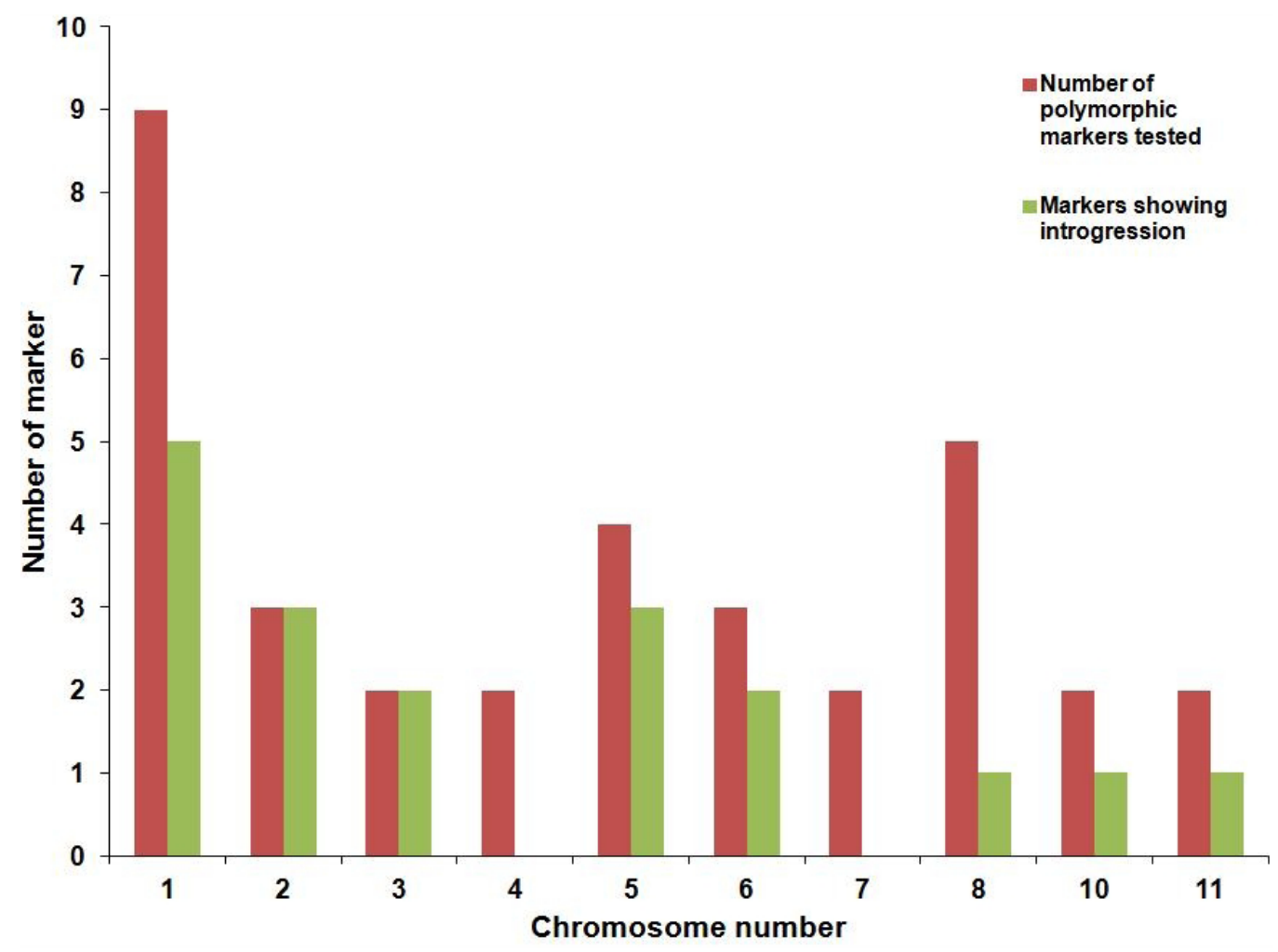

Figure 3. Proportion of microsatellite markers that showed introgression from Oryza rufipogon in all the 10 selected variants.

For all chromosomes, introgression varied from one marker (chromosomes 8,10 and 11) to five markers (chromosome 1) in 10 variants. Alien segments were identified for all the variants. While G4 carried only two O. rufipogon markers, G8 carried eight markers. The level of heterozygous segments varied from 3 segments in G25 to 0 in G7 (Table 4). Based on the marker profile, the graphical genotypes marking the chromosome segments from the two parental species were generated for each of the introgression lines (Figure 4). Graphical GenoTypes (GGT) analysis results of the $\mathrm{BC}_{2} \mathrm{~F}_{7}$ variants showed an average recovery of $83.3 \%$ of the MR219 genome while that of $O$. rufipogon was $11.4 \%$ with a residual heterozygosity of $2.8 \%$ (Table 4 ).

\section{Physicochemical properties in relation to alien introgressed regions}

As described in the previous section, not only did grain density show a nonsignificant difference between the variants, but also no introgression could be found for this trait 
among variants, which was the same for the filled rough rice ratio trait. Although milled rice percentage was not significant, introgressed segments could be detected for G7, G8, G9, G19, G25, and G26 at RM26 on chromosome 5. G7 had additional introgression in the region marked by RM239 on chromosome 10 . Variant G13 showed significantly higher de-husked rice percentage relative to MR219 (Table 2), and one introgressed segment was found on chromosome 1 at the RM297 locus. One of the variants (G7) carried the $O$. rufipogon allele at RM239 on chromosome 10 but failed to show differences compared to the recurrent parent for de-husked rice percentage. All samples had higher head rice percentage relative to MR219. Although no chromosome segment could be detected for G4 and G19, they showed higher head rice percentage compared to MR219. The common introgressed segments in lines G13 and G16 were marked by RM5 on chromosome 1 and RM263 and RM13345 on chromosome 2. Variants G7, G9, G15, G25, and G26 had one $O$. rufipogon allele at different loci. A great number of introgression segments were detected on chromosome 1 for broken rice (Figure 4). All variants showed a lower broken grain percentage ( $<30 \%$ ) compared to MR219 (39.2\%). Variants G8, G13, G15, and G26 shared a common introgression pattern with O. rufipogon alleles at RM23 and RM493 for broken rice percentage. Additional introgression at locus RM572 (chromosome 1) could be detected for lines G8, G15 and G26 while G13, lacking the O. rufipogon allele in this region. Variants G13 and G16 shared common introgressed segments, which are marked

\begin{tabular}{|c|c|c|c|c|c|c|}
\hline Variant & A $(\%)$ & B $(\%)$ & $\mathrm{H}(\%)$ & $\mathrm{U}(\%)$ & Total (cM) & H-segments \\
\hline G4 & 99.0 & 0.4 & 0.6 & 0 & 539.0 & 1 \\
\hline G7 & 86.8 & 11.4 & 0 & 1.8 & 539.0 & 0 \\
\hline G8 & 74.6 & 18.1 & 1.8 & 5.6 & 539.0 & 1 \\
\hline G9 & 78.4 & 3.9 & 0.4 & 17.3 & 539.0 & 1 \\
\hline G13 & 70.9 & 25.4 & 3.7 & 0 & 539.0 & 1 \\
\hline G15 & 79.0 & 11.7 & 9.3 & 0 & 539.0 & 1 \\
\hline G16 & 83.1 & 16.2 & 0.7 & 0 & 539.0 & 1 \\
\hline G19 & 93.2 & 4.2 & 2.6 & 0 & 539.0 & 1 \\
\hline G25 & 93.8 & 0 & 6.2 & 0 & 539.0 & 3 \\
\hline G26 & 73.7 & 22.9 & 2.6 & 0.9 & 539.0 & 1 \\
\hline Average & 83.3 & 11.4 & 2.8 & 2.6 & & \\
\hline
\end{tabular}

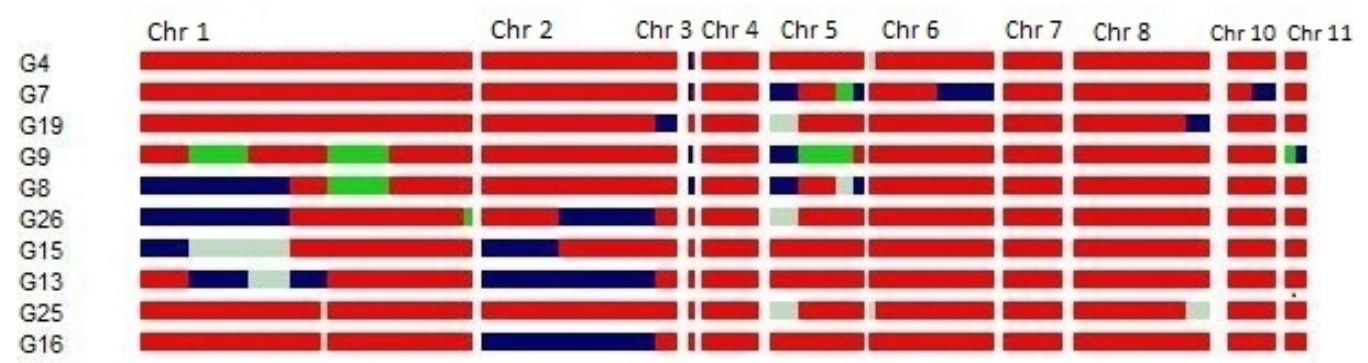

Figure 4. Graphical genotypes of the 10 introgression lines showing the 10 rice chromosomes. Red squares represent the recurrent parent (Oryza sativa) proportion of the genome. Blue squares represent the wild (Oryza rufipogon) homozygous introgressions, gray squares are the heterogeneous introgressions, and green squares represent missing data. 
by RM263 and RM13345 on chromosome 2. G8 had two introgressed segments at loci RM178 and RM334 (chromosome 5). Variants G7, G15 and G26 had introgressed segments at RM334, RM13345 and RM263, respectively. Variants G7, G9 and G13 had lower protein content relative to the recurrent parent. In these lines, the introgressed segments were marked by RM253 on chromosome 6, RM229 on chromosome 11 and RM297 on chromosome 1, respectively. G19 had one segment on chromosome 2 by RM240 and similar protein content as MR219. The same trend as protein content was evident for amylose content. Lines G4, G7, G8, G19, and G25 had introgressed segments from O. rufipogon but showed lower amylose content, but not G9. The set of 10 lines reported here may not show an obvious illustration of grain quality effects of individual markers or QTL, but an indirect assumption can be made for the three markers RM263, RM13345, and RM178. These markers were used simultaneously for genotyping percentage of head rice and broken rice grains, probably responding to selection for samples.

\section{DISCUSSION}

Selection of parental lines having the desirable traits that will face the objective of the breeder is the first step in crop improvement. This is followed by making crosses between the parents to produce a segregating population. Selection of progeny indicating the desirable traits then initiates and continues as the population is advanced from one generation to the next. Introgression of one or more genes from a donor into the background of an elite variety (recurrent or recipient parent) and to improve the recurrent parent genome as quickly as possible is one of the main objectives of plant breeding. There are several ways to introgress useful genes from a wild relative to a cultivated variety, generally on the basis of backcrosses and selection for the trait phenotype. The $O$. rufipogon segments identified in 10 introgression lines also need to be viewed in light of information from related studies. Differences in the quantity of the fibrous husk, which encloses the rice grain, were also pronounced between rice variants. The lemma and palea of the rice husk are maternal tissues (Shobha Rani et al., 2008). Normally the husk content is $20-22 \%$ of the rough rice, although a variation of 18 to $26 \%$ has been recorded (Shobha Rani et al., 2008). The variants tested showed significant difference in the percentage of de-husked rice grains. Recently, Bhonsle and Sellappan (2010) reported that the de-husking percentage for traditionally cultivated scented and basmati rice varieties ranged from 72 to 82 . Rice husks are considered an economically interesting source of natural antioxidants, prompting many studies to explain their biochemical mechanisms in protection against oxidative stress-caused damages (Butsat and Siriamornpun, 2010). Variant G13 carried the O. rufipogon allele for this trait (Figure 4). De-husked rice QTL (QTL-br1) in this region has also been mapped in the interval RM297-RM315 (Aluko et al., 2004). RM239 on chromosome 10 is another marker for which introgression was identified in G7 in this study. Septiningsih et al. (2003) detected one QTL for brown rice in the interval RM474-RM239 in an $O$. sativa IR64 x O. rufipogon cross. Graphical genotyping software programs, such as GGT (van Berloo, 2008), are very useful tools for selecting preferable backcross progeny on the basis of their genotypic content.

Head rice percentage is an inherited trait, even though environmental factors such as temperature and humidity during ripening and postharvest stages are known to affect grain breakage during milling (Shobha Rani et al. 2008). The head rice grain percentage showed 
the greatest variation ranging from 60.2 to 88.5. A similar result was obtained by Shobha Rani et al. (2008). Li et al. (2008) reported that head rice yield for indica rice (O. sativa L., cv. Liangyou 2186) as a control was $63.8 \%$. Unexpectedly, the effect of the wild alleles was beneficial, suggesting that they are associated with more stability of grains during milling. Aluko et al. (2004) found three chromosomal regions associated with QTLs for head rice percentage, which were in the same region as in this study. Septinigsih et al. (2003) found 2 QTLs by RM263 on chromosome 2 and RM178 on chromosome 5 with the beneficial alleles coming from $O$. sativa in both cases.

Many grains are lost as a result of shattering and are cracked throughout threshing if the harvest is too late, which results in grain breakage during milling (http://www.knowledgebank. irri.org/rkb/index.php/quality-characteristics-of-paddy). The percentage of broken rice grains ranged from 11.1 to 39.2. Sarker and Farouk (1989) reported that long grain varieties are more vulnerable to breakage during milling compared to short grain varieties, and this may also account for the lower head rice yield. It has also been reported that the mass loss and breakage are influenced by the cultivar, kernel shape, and thickness of the aleurone layer (Juliano, 1972). Diako et al. (2011) reported that broken rice percentage for four commercial Ghanaian rice varieties was $13.60-32.70 \%$. As expected, the amount of broken grains was negatively correlated with head rice percentages $(\mathrm{r}=-0.99, \mathrm{P}<0.01)$. A similar correlation was also reported by Septiningsih et al. (2003). Introgression lines with O. rufipogon segments at different loci showed a decreasing effect on broken grains. Broken grain QTL in these regions has also been mapped in cultivated germplasm (Septiningsih et al., 2003). The main advantages of the Kjeldahl method for food protein analysis are its high level of precision, its compatibility with nearly all food matrices, its wide recognition in the food analytical and regulatory communities, and its options for automation (Moore et al., 2010). Protein, an important factor affecting the eating quality of rice, was considerably high $(>7 \%)$ for all variants (Table 2). Significant differences $(\mathrm{P}<0.05)$ existed in the protein contents among all variants. Eggum and Juliano $(1975)$ reported that high levels of fertilizer increase total protein content. Other factors such as short growth periods, soil salinity or alkalinity may also increase the protein content of grain. A large proportion of the total variability in protein content is attributable to environment (Shobha Rani et al., 2006). The range of protein content values obtained in the present study (Table 2) was slightly higher than that reported by Juliano and FAO (1993) (7.3-8.6\%), Yadav et al. (2007) (5.46-7.02\%), and Eggum et al. (1993) (7.1-8.7\%). The ranges obtained for the samples fall within that for polished rice (6.78-10.5\%) (Adu-Kwarten et al., 2003).

Increasing the protein content values in this cereal as a result raises protein intake, particularly in countries where rice is consumed as the staple food (Perez et al., 1996). On the basis of the differences found between variants in different environments and to the abovementioned views, the hypothesis is raised that some of the rice variants could be used to contribute to higher or lower protein intake, based on certain needs of each individual (i.e., higher protein intake to contribute to growth; smaller protein intake to control kidney problems). RM253 on chromosome 6 and RM229 on chromosome 11 are markers for which introgression was identified in this study and whose wild parent allele has been previously shown by Aluko et al. (2004) to have a negative effect on protein content. In fact, three introgression lines G7, G9 and G13, which carried the O. rufipogon segment, showed lower protein content relative to MR219. However, not all the lines carrying the O. rufipogon segment showed this negative effect, probably due to other introgressed regions providing a neutralizing or negative influ- 
ence. One of the progenies (G19) carried the O. rufipogon allele at RM240 but failed to show any significant increase in protein content over the recurrent parent.

The amylose content of the rice starch is an important eating quality factor. It is directly associated with volume expansion and water absorption during cooking and with hardness, whiteness and dullness of cooked rice. Genetic studies have indicated that the nonwaxy trait dominates over the waxy trait (Kumar and Khush, 1987). Among nonwaxy parents, high amylose is completely dominant over low or intermediate amylose, and intermediate is dominant over low (Kumar and Khush, 1987). The statistical results pertaining to amylose content of different rice variants are presented in Table 2. The amylose content ranged from 18.4 to $25.7 \%$ among the rice variants. This range is narrower than that reported by Kennedy and Burlingame (2003) (0.5-33\%), who described the amylose content of 2000 rice varieties. González et al. (2004) reported amylose values of $20.5-26.7 \%$ for eight milled rice varieties, obtained by the DSC method. The amylose content was found to be higher in G13 followed by G15, and the lowest amylose content was observed in G25 across all samples. In the present study, the average amylose content for all samples except G7 and G25 was intermediate, which correlates with extreme elongation during cooking and soft texture of cooked rice. Aluko et al. (2004) detected three QTLs, amy3, amy6 and amy8 on chromosomes 3, 6 and 8 in the intervals RM7RM251, RM190-RM253 and RM230-RM264, respectively, to enhance amylose content in the same region as in this study. Other researchers have also detected a QTL for amylose content in the same region of the interval RM190-RM253 near the waxy gene on chromosome 6 (He et al., 1999; Tan et al., 1999; Lanceras et al., 2000; Septiningsih et al., 2003). Thus, the lack of an increase in amylose content in variants G4, G7, G8, G19, and G25 might have been due to a neutralizing effect of both positive and negative alleles from $O$. rufipogon. Introgression line G9, which carried O. rufipogon alleles at RM7 and RM251, failed to show variation in amylose content with respect to the recurrent parent. Previous studies based on mapping populations derived from $O$. sativa $\mathrm{x} O$. sativa crosses detected QTLs controlling amylose content on chromosomes other than chromosome 6 (He et al., 1999; Lanceras et al., 2000). These results support the idea that both the major waxy gene and modifying genes control amylose content, as previously reported by Mckenzie and Rutger (1983).

Grain quality characteristics of new varieties are always compared to those of comparably grown leading commercial varieties of appropriate grain type. If, after a number of years or at several locations, characteristics of new varieties resemble or are superior to those of standard varieties, they are assessed as having acceptable or distinguished cooking and processing quality; if not, they are judged undesirable or of unknown quality (Owens, 2001). On the whole, the majority of $O$. rufipogon alleles that were common with other studies seemed to be effective across recipient genotypes. The evaluation of test cross progeny as attempted by Xiao et al. (1998) may identify some QTL that may have positive effects in heterozygous conditions and not in homozygous conditions as illustrated by Semel et al. (2006). These alleles seem novel and are not common in cultivated germplasm. The idea of segmental introgression lines has been developed in tomato to improve rate of progress of breeding on the basis of wild species resources. Superiority or positive effects that are retained after the alien segments become homozygous are the ones that can be quickly achieved in the form of improved pure line variety. In the present study, the introgressed segments of $O$. rufipogon increased the head rice percentage and showed a positive effect on decreasing the amount of broken rice percentage in all variants, while remaining at the MR219 level for other traits. The situation clearly propagates 
the likelihood of incorporating the improvements for the two components in a single genotype.

\section{ACKNOWLEDGMENTS}

Research supported by the Ministry of Science, Technology and Innovation (MOSTI) (Project \#UKM-ABI-NBD0001-2007). Dr. Atiqur Bhuiyan, Ms. Mee Siing and UPMBERNAS Research Laboratory staff are gratefully acknowledged for their cooperation.

\section{REFERENCES}

Adu-Kwarten E, Ellis WO, Oduro I and Manful JT (2003). Rice grain quality: a comparison of local varieties with new varieties under study in Ghana. Food Control. 14: 507-514.

Aluko G, Martinez C, Tohme J, Castano C, et al. (2004). QTL mapping of grain quality traits from the interspecific cross Oryza sativa x O. glaberrima. Theor. Appl. Genet. 109: 630-639.

Bhonsle SJ and Sellappan K (2010). Grain quality evaluation of traditionally cultivated rice varieties of Goa, India. Recent Res. Sci. Technol. 2: 88-97.

Bhuiyan MAR, Narimah MK, Abdul Rahim H, Abdullah MZ, et al. (2011). Transgressive variants for red pericarp grain with high yield potential derived from Oryza rufipogon x Oryza sativa: Field evaluation, screening for blast disease, QTL validation and background marker analysis for agronomic traits. Field Crops Res. 121: 232-239.

Brar DS and Khush GS (1997). Alien introgression in rice. Plant Mol. Biol. 35: 35-47.

Butsat S and Siriamornpun S (2010). Antioxidant capacities and phenolic compounds of the husk, bran and endosperm of Thai rice. Food Chem. 119: 606-613.

Diako C, Manful JT, Johnson PNT, Sakyi-Dawson E, et al. (2011). Physicochemical characterization of four commercial rice varieties in Ghana. Adv. J. Food Sci. Technol. 3: 196-202.

Eggum BO and Juliano BO (1975). Higher protein content from nitrogen fertiliser application and nutritive value of milled-rice protein. J. Sci. Food Agr. 26: 425-427.

Eggum BO, Juliano BO, Perez CM and Acedo EF (1993). The resistant starch, undigestible energy and undigestible protein contents of raw and cooked milled rice. J. Cereal Sci. 18: 159-170.

Frey KJ, Cox TS, Rodgers DM and Cox PB (1983). Increasing Cereal Yields With Genes From Wild and Weedy Species. Proceedings of the 15th International Genetics Congress. Oxford and IBH Publishing Co., New Delhi, 51-68.

González RJ, Livore A and Pons B (2004). Physico-chemical and cooking characteristics of some rice varieties. Braz. Arch. Biol. Techn. 47: 71-76.

He P, Li SG, Qian Q, Ma YQ, et al. (1999). Genetic analysis of rice grain quality. Theor. Appl. Genet. 98: 502-508.

ISO/DIS 6647-1 (2005). Determination of Amylose Content, Part 1. Reference Method. 2005.

ISO/DIS 6647-2 (2005). Determination of Amylose Content, Part 2. Routine Method, 2005.

Juliano BO (1972). Physicochemical Properties of Starch and Protein in Relation to Grain Quality and Nutritional Value of Rice. In: Rice Breeding. International Rice Research Institute, Los Banos, 389-405.

Juliano BO and FAO (1993). Rice in Human Nutrition. FAO, Rome. Available at [http://www.fao.org/inpho/content/ documents//vlibrary/t0567e/t0567e00.htm]. Accessed January 14, 2004.

Kennedy G and Burlingame B (2003). Analysis of food composition data on rice from a plant genetic resources perspective. Food Chem. 80: 589-596.

Kumar I and Khush GS (1987). Genetic analysis of different amylose levels in rice. Crop Sci. 27: 1167-1172.

Lanceras JC, Huang ZL, Naivikul O, Vanavichit A, et al. (2000). Mapping of genes for cooking and eating qualities in Thai jasmine rice (KDML105). DNA Res. 7: 93-101.

Li X, Huang K, Zhu B, Liang Z, et al. (2008). Comparative physicochemical properties and structure of rice containing the sck+cryIAc genes and its nontransgenic counterpart. J. Food Sci. 73: S64-S69.

Mckenzie KS and Rutger JN (1983). Genetic analysis of amylose content, alkali spreading score, and grain dimension in rice. Crop Sci. 23: 306-311.

Moore JC, DeVries JW, Lipp M, Griffiths JC, et al. (2010). Total protein methods and their potential utility to reduce the risk of food protein adulteration. Compr. Rev. Food Sci. Food Saf. 9: 330-357.

MS1 194 (1991). Methods for Determination of Crude Protein in Foods and Feeds. Malaysian Standard, SRIM, Malaysia.

Murray MG and Thompson WF (1980). Rapid isolation of high molecular weight plant DNA. Nucleic Acids Res. 8: 4321-4325. Oka HI (1988). Origin of Cultivated Rice. Scientific Societies Press, Tokyo. 
Owens WG (2001). Wheat, Corn and Coarse Grains Milling. In: Cereals Processing Technology (Owens WG, ed.). Woodhead Publishing Ltd., Cambridge, 27-52.

Panaud O, Chen X and McCouch SR (1996). Development of microsatellite markers and characterization of simple sequence length polymorphism (SSLP) in rice (Oryza sativa L.). Mol. Gen. Genet. 252: 597-607.

Perez RG, Squazzo SL and Koo EH (1996). Enhanced release of amyloid beta-protein from codon 670/671 "Swedish" mutant beta-amyloid precursor protein occurs in both secretory and endocytic pathways. J. Biol. Chem. 271: 9100-9107.

RTWG (Rice Technical Working Group) (1997). National Cooperative Testing Manual for Rice: Guidelines and Policies. Philippine Rice Research Institute, Muñoz.

Sarker NN and Farouk SM (1989). Some factors causing rice milling loss in Bangladesh. Agric. Mech. Asia Afr. Latin Am. 20: 49-52,56.

Semel Y, Nissenbaum J, Menda N, Zinder M, et al. (2006). Overdominant quantitative trait loci for yield and fitness in tomato. Proc. Natl. Acad. Sci. U. S. A. 103: 12981-12986.

Septiningsih EM, Prasetiyono J, Lubis E, Tai TH, et al. (2003). Identification of quantitative trait loci for yield and yield components in an advanced backcross population derived from the Oryza sativa variety IR64 and the wild relative $O$. rufipogon. Theor. Appl. Genet. 107: 1419-1432.

Shobha Rani N, Madhav SM, Sundaram MKPRM, Prasad GSV, et al. (2008). Genetics and molecular approaches for improvement of grain quality in rice. Indian J. Crop. Sci. 3: 1-14.

Tan YF, Li JX, Yu SB, Xing YZ, et al. (1999). The three important traits for cooking and eating quality of rice grains are controlled by a single locus in an elite rice hybrid, Shanyou 63. Theor. Appl. Genet. 99: 642-648.

Tanksley SD, Grandillo S, Fulton TM, Zamir D, et al. (1996). Advanced backcross QTL analysis in a cross between an elite processing line of tomato and its wild relative L. pimpinellifolium. Theor. Appl. Genet. 92: 213-224.

Thomson MJ, Tai TH, McClung AM, Lai XH, et al. (2003). Mapping quantitative trait loci for yield, yield components and morphological traits in an advanced backcross population between Oryza rufipogon and the Oryza sativa cultivar Jefferson. Theor. Appl. Genet. 107: 479-493.

van Berloo R (2008). GGT 2.0: versatile software for visualization and analysis of genetic data. J. Hered. 99: 232-236.

Xiao J, Grandillo S, Ahn SN, McCouch SR, et al. (1996). Genes from wild rice improve yield. Nature 384: 223-224.

Xiao J, Li J, Grandillo S, Ahn SN, et al. (1998). Identification of trait-improving quantitative trait loci alleles from a wild rice relative, Oryza rufipogon. Genetics 150: 899-909.

Wickneswari R, Sabu KK, Lim LS and Abdullah MZ (2003). Improvement of Grain Yield Using Advanced Backcross Strategy in a Malaysian Rice Variety. Proceedings of the XIX International Congress of Genetics, Melbourne, 54.

Yadav RB, Khatkar BS and Yadav BS (2007). Morphological, physicochemical and cooking properties of some Indian rice (Oryza sativa L.) cultivars. J. Agr. Tech. 3: 203-210. 